\title{
GOSSIPIBOMA INTRABDOMINAL: RELATO DE CASO ${ }^{1}$
}

\author{
CARDOSO, Fernando Alves ${ }^{2}$ \\ BARBOSA, Aldo Benjamim Rodrigues ${ }^{3}$ \\ CARDOSO, Denner Alves ${ }^{3}$ \\ PEREIRA, Rogério Silva ${ }^{3}$ \\ PEREIRA, Flávio Cardoso ${ }^{2}$
}

\begin{abstract}
RESUMO: Os gossipibomas são corpos estranhos intrabdominais formados de algodão. Trata-se de um evento subnotificado devido às implicações médico-legais envolvidas. Apresenta um quadro clínico variável e muitas vezes confuso, pois depende diretamente do comportamento do organismo frente ao corpo estranho. A tomografia computadorizada de abdome é o método diagnóstico padrão ouro que deve ser solicitada na suspeita clínica. Pretende-se neste relato, alertar aos cirurgiões quanto à possibilidade diagnóstica através de uma relato de caso clínico e uma breve revisão da literatura relevante.
\end{abstract}

Palavras-Chave: Corpo estranho. Cirurgia abdominal. Tomografia computadorizada.

SUMMARY: The foreign intrabdominais gossipibomas are formed of cotton. This is an event underreported due to medicolegal implications involved. Presents a clinical variable and often confusing, since it depends directly from the behavior of the organism against the foreign body. Computed tomography of the abdomen is the diagnostic gold standard should be applied on clinical suspicion. It is intended in this report, surgeons warn about the possible diagnosis through a clinical case report and brief review of relevant literature.

Keywords: Foreing body. Abdominal surgery. Computed tomography

\section{INTRODUÇÃO}

Os corpos estranhos intrabdominais são complicações possíveis de procedimentos cirúrgicos e os relatos na literatura médica são escassos, provavelmente secundários as implicações legais existentes; sendo um material riquíssimo a ser explorado pela imprensa em geral (CARVALHO; VINHAES, 2004) Há fatores de riscos associados a esta condição tais como: cirurgia de emergência, intercorrência inesperada no ato cirúrgico e obesidade (SHAUKAT et al., 2009).

Os gossipibomas apresentam uma alta morbi-mortalidade, um quadro clínico confuso e uma história natural variável, graças ao comportamento do organismo frente ao corpo estranho que em muitas vezes retardam o diagnóstico pré operatório, sendo assim, necessária a realização de uma laparotomia exploradora (CARVALHO; VINHAES, 2004; SHAUKAT et al., 2009).

Pretende-se neste relato, alertar aos cirurgiões quanto a possibilidade diagnóstica e realizar uma breve revisão da literatura dos gossipibomas (MEFIRE, A.C. et al.).

\section{RELATO DE CASO}

Paciente ERS, masculino, 36 anos, branco, procedente de Catanduva, São Paulo, com quadro de dor abdominal difusa há 2 anos, associado a infecções do trato urinário de repetição. Há 9 anos foi submetido a uma laparotomia exploradora devido a ferimento por arma branca com lesões hepáticas, gástrica e vesicular que foram rafiadas neste ato. O pós operatório transcorreu sem intercorrências. Ao exame físico apresentava abdome globoso e sem sinais de irritação peritoneal, com dor a palpação

\footnotetext{
${ }^{1}$ Trabalho Realizado pelos Departamentos de Cirurgia e Radiologia da Santa Casa de Misericórdia de Ituverava, São Paulo, Brasil.Praça Monsenhor João Rulli s/n CEP: 14500-000

${ }^{2}$ Médico Cirurgião da Santa Casa de Misericórdia de Ituverava

${ }_{3}^{3}$ Médico Radiologista da Santa Casa de Misericórdia de Ituverava
} 
profunda no hipogástrio, onde se observou massa de consistência pétrea e fixa medindo aproximadamente $10,0 \mathrm{~cm}$.

\section{ASPECTO DE IMAGEM}

O estudo tomográfico do abdome mostra lesão heterogênea, de contornos definidos e regulares, localizada no hipogástrio anteriormente ao sacro e medindo aproximadamente $12,0 \times 10,0 \mathrm{~cm}$. A lesão desloca e comprime a bexiga urinária anteriormente. A hipótese diagnóstica foi de corpo estranho intrabdominal. (Figura 1)

Figura 1: Corte tomográfico axial do abdome inferior evidenciando massa heterogênea, bem definida, em contato com o sacro e deslocando a bexiga urinária anteriormente. (setas)

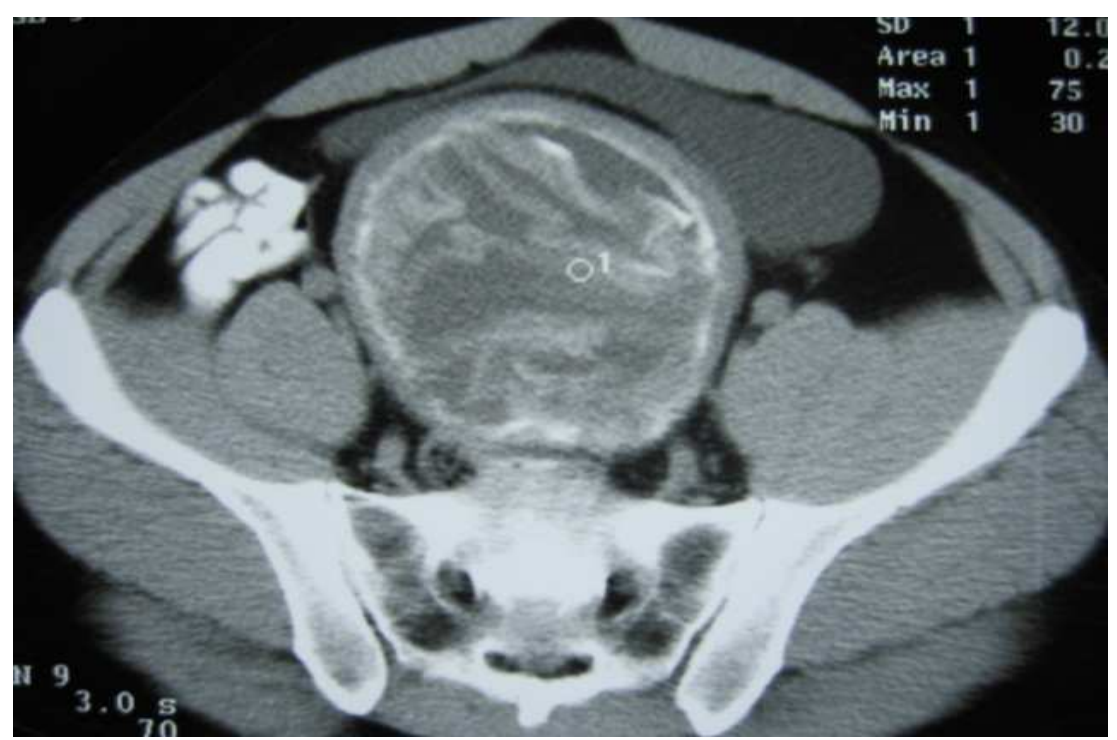

Fonte: Arquivo pessoal.

\section{ACHADOS CIRÚRGICOS}

Realizado laparotomia exploradora com incisão mediana, sendo visualizada massa fibrótica e capsulada localizada na região suprapúbica e parcialmente aderida ao sigmóide e a bexiga. No seu interior, notam-se compressas envoltas pos cápsula fibrótica e densa. (Figura 2)

Figura 2: Peça cirúrgica aberta observando gossipiboma com carapaça fibrótica e lisa. (setas)

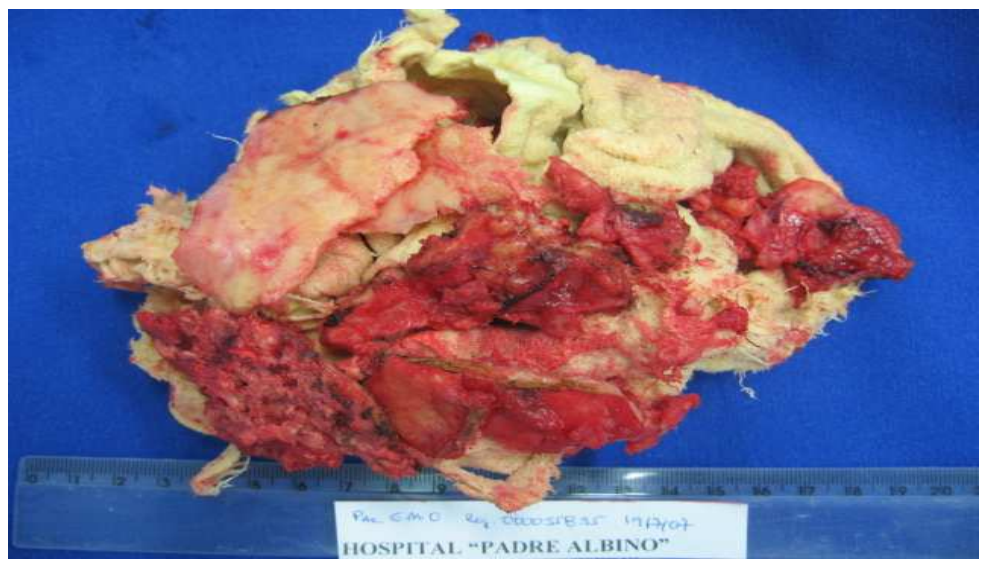

Fonte: Arquivo Pessoal 


\section{DISCUSSÃO}

Os corpos estranhos intrabdominais foram descritos primeiramente por Wilson et al em 1884. Apresentam uma incidência em torno de 1:1000 a 1:5000 laparotomia, porém este número é subnotificado devido as implicações legais envolvidas nestas situações, sendo abordada na maioria dos casos com negligência médica pela opinião pública e não como uma possível complicação do ato operatório. A culpabilidade do cirurgião merece uma discussão mais profunda, pois engloba uma série de fatores e conforme abordada pelos professores Forgue e Aimes na década de 60; "O abandono, em corpo vivo, de um material de operação não é, em Justiça, uma presunção de culpabilidade, nem uma falta sistematicamente imputável." (CARVALHO; VINHAES, 2004 , MARTINS et al., 2009).

Os mais diferentes tipos de materiais podem sem encontrados no abdome, sendo os têxteis, compressas e gazes, os mais comuns, numa incidência de 48 a 91\% dos casos. (SHAUKAT et al., 2009; MARTINS et al., 2009; VERMA; MOHAN; BAIJAL, 2007). O termo gossipiboma, oriundo do latim (Gossypium: algodão e Boma: local de ocultação) é usado para descrever uma massa formada a partir de uma matriz de algodão cercada por uma reação inflamatória e granulomatosa. Outros sinônimos utilizados são: textiloma, gauzoma e compressoma. (TOPAL et al., 2011)

Em geral, as compressas intrabdominais podem: encapsular-se; serem eliminadas pela incisão ou migrar-se para o lúmen intestinal, sendo esta a evolução mais incomum (CARVALHO; VINHAES, 2004; MEFIRE et al 2010; TOPAL et al., 2011). Histologicamente pode ocorrer uma reação séptica/exsudativa ou uma reação asséptica/fibrinosa, que são responsáveis pela sintomatologia variada encontrada nestes pacientes. A primeira é reconhecida precocemente porque os sinais e sintomas são mais exuberantes, pois os corpos estranhos podem servir de nicho de proliferação de microorganismo, agindo como foco de abscesso e peritonite. (VERMA; MOHAN; BAIJAL, 2007). A segunda pode ficar oculta por anos; pois o algodão sendo um material inerte, ocorre deposição de fibrina, formando uma carapaça. (CARVALHO; VINHAES, 2004; SHAUKAT et al., 2009; TOPAL et al., 2011) Em alguns casos, pode ocasionar efeito de massa, comprimindo órgãos e estruturas como os rins e bexiga. (TOPAL et al., 2011)

O quadro clínico é variável, dependendo da localização da compressa, do tipo da reação do organismo em relação ao corpo estranho e do estado imunológico do paciente. Os sinais e sintomas mais comuns são: dor abdominal, massa palpável, náuseas e vômitos, perda ponderal, abscessos, fístulas, suboclusão e obstrução. (CARVALHO; VINHAES, 2004; SHAUKAT et al., 2009; MEFIRE et al, 2009). É uma causa incomum de febre de origem desconhecida (VERMA; MOHAN; BAIJAL, 2007). Não se observa peritonite difusa, pois aderências compartimentaliza a cavidade abdominal. Dependendo da localização dos gossipibomas, podem-se encontrar queixas como: refluxo gastroesofágico, polaciúria e infecções urinárias de repetição (SCHANAIDER; MANSO, 2006).

Os principais fatores de risco envolvidos são: cirurgia ginecológica, cirurgia de emergência, mudança inesperada do ato cirúrgico, mais de uma equipe cirúrgica envolvida, mudança de equipe de enfermagem, obesidade, hemorragia interna, sexo feminino e contagem errônea. (SHAUKAT et al., 2009; VERMA; MOHAN; BAIJAL, 2007; IGLESIAS; SALOMÃO, 2007).

A investigação radiológica se baseia na radiologia convencional, ultrassonografia (US), tomografia comupatorizada (TC) e na ressonância magnética (RM).

$\mathrm{Na}$ radiologia convencional, o estudo radiológico do abdome agudo se pode caracterizar o fio radiopaco existentes em alguns tipos de compressas, além de sinais radiológicos de possíveis complicações como a obstrução intestinal. (SCHANAIDER; MANSO, 2006).

A US nos mostra uma massa com forte sombra acústica descrita por alguns autores como "sombra suja" (SCHANAIDER; MANSO, 2006). 
A TC de abdome oferece maior acurácia diagnóstica, sendo o padrão "ouro" para o diagnóstico dos gossipiboma e de suas complicações. O aspecto típico de imagem é a aparência espongiforme com pequenas bolhas de ar de permeio, podendo ser envolvida por uma carapaça com focos de calcificações. (IGLESIAS; SALOMÃO, 2007; SCHANAIDER; MANSO, 2006). Os principais diagnóstico diferenciais são: abscessos e neoplasias.

$\mathrm{Na} \mathrm{RM}$, a intensidade de sinal da imagem depende da quantidade de fluido e proteína associada a lesão que varia de acordo ao tempo em que o corpo estranho está no abdome, de sua localizadação anatômica e do tipo do material. Na maioria dos casos se apresenta como lesão bem definida, com uma cápsula espessa, baixo sinal nas sequências ponderadas em T1 e com intensidade elevada nas sequencias em T2. (MARTINS et al., 2010; IGLESIAS; SALOMÃO, 2007)

Após a realização do diagnóstico, o corpo estranho deve ser retirado quando a sintomatologia é relevante, na alteração da função do órgão, ou se houver alteração da qualidade de vida do paciente (SHAUKAT et al., 2009). Nos pacientes assintomáticos ou quando os corpos estranhos estão correlacionados com órgãos nobres devem ter um acompanhamento periódico (SHAUKAT et al., 2009).

Há medidas importantes para prevenção dos gossipibomas como: contagem e recontagem do número de compressas no pré-operatório imediato, trans-operatório e pós-operatório imediato; exploração exaustiva da cavidade abdominal antes da sutura peritoneal; utilizar somente material textil com marcação radiopaca; evitar uso de compressas pequenas e gases; anotar no prontuário do paciente o número de compressas intrabdominais diante de um "controle de danos", experiência da equipe cirúrgica, principalmente se houver necessidade de troca de seus membros em procedimentos de grande porte (IGLESIAS; SALOMÃO, 2007; SCHANAIDER; MANSO, 2006).

\section{CONCLUSÃO}

Gossipiboma são complicações do ato cirúrgico que podem ocasionar problemas legais entre o médico e o paciente. Medidas preventivas podem ser adotadas para se evitar tal problema, mas na suspeita clínica, o diagnóstico precoce e o tratamento correto alicerçado em uma boa relação médicopaciente, com certeza minimizará os prejuízos.

\section{REFERÊNCIA}

CARVALHO, J. B. de; VINHAES, J. C.. Corpo estranho retido na cavidade abdominal durante onze anos. Rev. Col. Bras. Cir. [online]. 2004, v.31, n.1, pp. 68-70. ISSN 0100-6991. http://dx.doi.org/10.1590/S0100-69912004000100013.

IGLESIAS, A. C.; SALOMAO, R. M.. Gossipiboma intra-abdominal: análise de 15 casos. Rev. Col. Bras. Cir. [online]. 2007, v.34, n.2, pp. 105-113. ISSN 0100-6991. http://dx.doi.org/10.1590/S0100-69912007000200008.

MARTINS, M. C. B. et al. Características de imagem na ressonância magnética de gossipiboma intracraniano: relato de caso e revisão da literatura. Radiol Bras [online]. 2009, vl.42, n.6, pp. 407-409. ISSN 0100-3984. http://dx.doi.org/10.1590/S0100-39842009000600016.

MEFIRE, A.C. et al.. Retained sponge after abdominal surgery: experience froam a third word country. Pan African Medical Journal, v.2, n.10, 2009. 
SCHANAIDER, A.; MANSO, J. E. F.. Corpos estranhos provenientes de acessos cirúrgicos à cavidade abdominal: aspectos fisiopatológicos e implicações médico legais. Rev. Col. Bras. Cir. [online]. 2006, v.33, n.4, pp. 250-255. ISSN 0100-6991. http://dx.doi.org/10.1590/S010069912006000400011.

SHAUKAT, A. et al. Diagnosing Gossypiboma of Abdomen. A.P.M.C v.3, n.2, 135-138, jul./dez. 2009. Disponível em: http://www.pmc.edu.pk/Downloads/apmc/apmc_v3n2/11DIAGNOSING\%20GOSSYPIBOMA\%20OF\%20ABDOMEN.pdf.

TOPAL, F. et al.. Intra-abdominal gossypiboma. Cumhuriyet Med Journal. v.33, p. 239-242, 2011.

VERMA A, MOHAN S, BAIJAL SS. Pyrexia of Unknown Origin Caused by Retained Intrabdominal Foreing Body: Report of a case with review of literature. Journal of Clinical and Diagnostic Research. v.1, n.3, p.152-162, 2007. 
